Stępińska Katarzyna. A patient with appendicitis acuta? Journal of Education, Health and Sport. 2022;12(1):192-196. eISSN 23918306. DOI http://dx.doi.org/10.12775/JEHS.2022.12.01.015

https://apcz.umk.pl/JEHS/article/view/JEHS.2022.12.01.015

https://zenodo.org/record/5866570

The journal has had 40 points in Ministry of Education and Science of Poland parametric evaluation. Annex to the announcement of the Minister of Education and Science of December 1, 2021. No. 32343. Has a Journal's Unique Identifier: 201159. Scientific disciplines assigned: Physical Culture Sciences (Field of Medical sciences and health sciences); Health Sciences (Field of Medical Sciences and Health Sciences).

Punkty Ministerialne z 2019 - aktualny rok 40 punktów. Zalącznik do komunikatu Ministra Edukacji i Nauki z dnia 1 grudnia 2021 r. Lp. 32343. Posiada Unikatowy Identyfikator Czasopisma: 201159. Przypisane dyscypliny naukowe:Nauki o kulturze fizycznej (Dziedzina nauk medycznych i nauk o zdrowiu); Nauki o zdrowiu (Dziedzina nauk medycznych i nauk o zdrowiu).

(1) The Authors 2022;

This article is published with open access at Licensee Open Journal Systems of Nicolaus Copernicus University in Torun, Poland

Open Access. This article is distributed under the terms of the Creative Commons Attribution Noncommercial License which permits any noncommercial use, distribution, and reproduction in any medium,

provided the original author (s) and source are credited. This is an open access article licensed under the terms of the Creative Commons Attribution Non commercial license Share alike.

(http://creativecommons.org/licenses/by-nc-sa/4.0/) which permits unrestricted, non

The authors declare that there is no conflict of interests regarding the publication of this paper.

Received: 02.01.2022. Revised: 17.01.2022. Accepted: 17.01.2022.

\title{
A patient with appendicitis acuta?
}

\section{Katarzyna Stępińska}

Uniwersytet Jagielloński w Krakowie

Key words: appendicitis acuta

\begin{abstract}
Acute appendicitis has always been correlated with a short patient's medical history and a sudden onset of symptoms. Nevertheless, in some patients the duration of the symptoms is prolonged, up to several days. The following case illustrates this course of the disease.
\end{abstract}

Do SOR zgłosił się 41-letni pacjent z powodu dolegliwości bólowych jamy brzusznej, które wystąpiły około 2 godzin po badaniu kolonoskopowym. Ból występował nad całą jamą brzuszną, był najbardziej nasilony w prawym podbrzuszu. Przy przyjęciu chory zgłaszał ponadto: nudności, uczucie wzdęcia, zatrzymanie gazów, niemożność oddania moczu z uczuciem parcia na pęcherz. Dolegliwości nie ustąpiły po przyjęciu leków rozkurczowych i przeciwbólowych.

Kolonoskopię pacjent wykonał $\mathrm{z}$ powodu trwających od 2 tygodni biegunek oraz dyskomfortu w prawym podbrzuszu. Badanie wykazało uchyłki esicy i guzki krwawnicze. Do badania chory przygotowywał się standardowo. 
W badaniu fizykalnym stwierdzono: otyłość; obecność perystaltyki na rozdętych pętlach nad całą jamą brzuszną; brzuch był miękki, nieco wzdęty, palpacyjnie tkliwy, z zaznaczoną obroną mięśniową nad prawym talerzem biodrowym.

W USG uwidoczniono:

\section{Pracownia wykonująca: PRACOWNIA USG}

Status: WykonaneUsługa zlecona: USG_JB, USG J.BRZUSZNEJ

\section{Opis z systemu diagnostycznego:}

B.dużo gazów w obrębie jamy brzusznej znacznie utrudniających badanie -narządy jamy brzusznej widoczne fragmentarycznie. Wątroba(powiększona AP o wym ok. $161 \mathrm{~mm}$, hyperechogenna najp. na tle stłuszczenia), śledziona(niepowiększona), trzustka(widoczna w zakresie części głowy i trzonuniepowiększona)jednorodne, bez wyraźnych zmian ogniskowych. Pęcherzyk żółciowy echoujemny. PŻW przesłonięty. Drogi żółciowe wewnątrzwątrobowe w uwidocznionym zakresie nieposzerzone. Nerki umiarkowanej wielkości bez wyraźnych cech zastoju i odbić typowych dla dużych złogów w UKM obustronnie. Pẹcherz moczowy ze śladem moczu. Aorta brzuszna nieposzerzona-widoczna fragmentarycznie. Okolica okołoaortalna przesłonięta. W okolicy prawego podbrzusza obecny wolny płyn o wym ok. $8,5 \mathrm{~mm}$. W obrębie całej jamy brzusznej widoczne szersze pętle jelitowe z cechami wahadłowej perystaltyki.

Natomiast w wykonanym RTG przeglądowym jamy brzusznej uwidoczniono: 


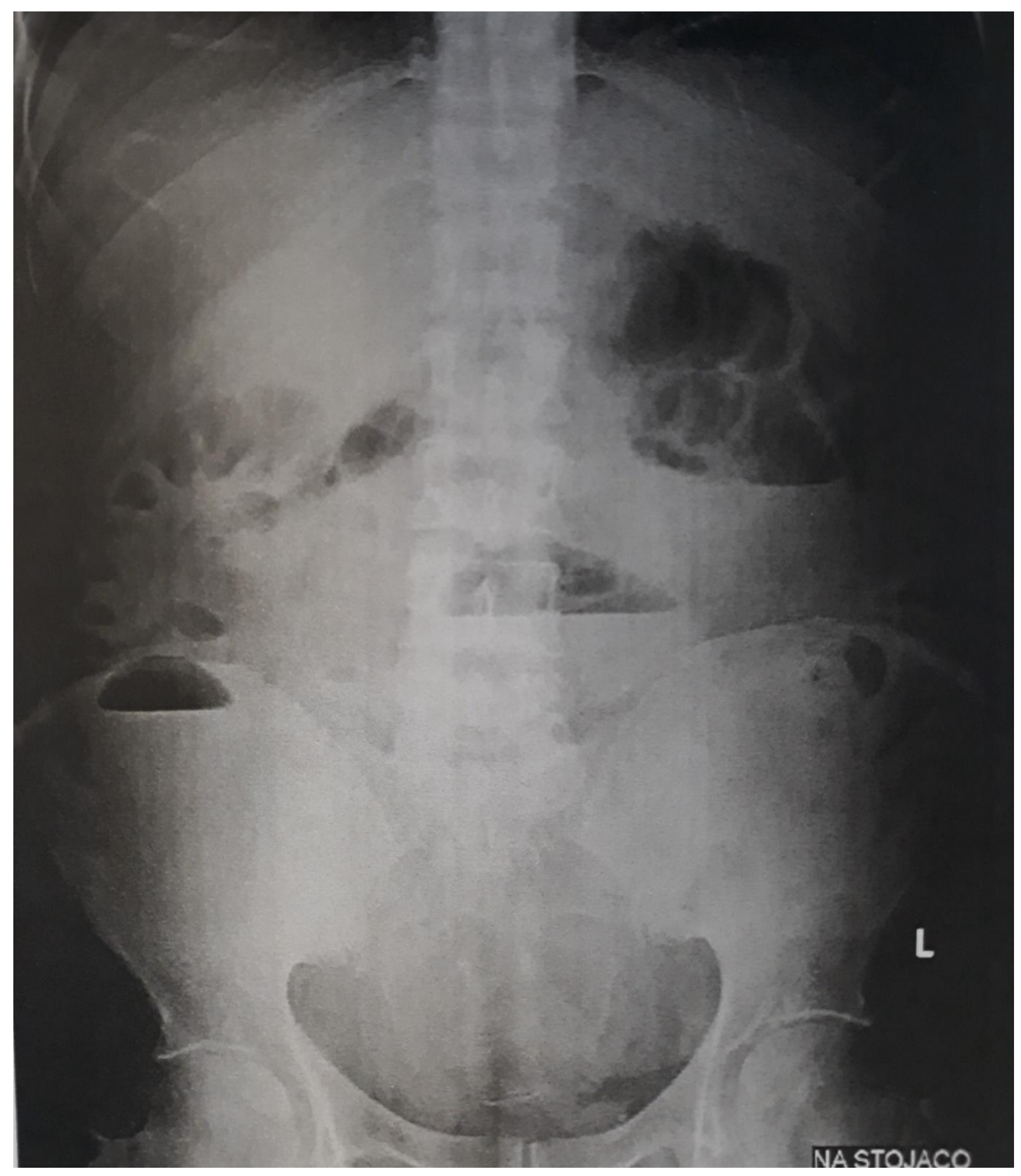

Pracownia wykonująca: ZAKŁAD RTG

Status: WykonaneUsługa zlecona: RTG_BKJ, RTG PRZEGLĄDOWE JAMY BRZUSZNEJ

Opis z systemu diagnostycznego:

Na zdjęciu przeglądowym jamy brzusznej wykonanym w pozycji stojącej w rzucie jamy brzusznej w rzucie nadbrzusza i śródbrzusza widoczne długie poziomy płynów.Poniżej lewej kopuły przepony widoczne przejaśnienie-na tle obecności bańki powietrza w żołądku? 

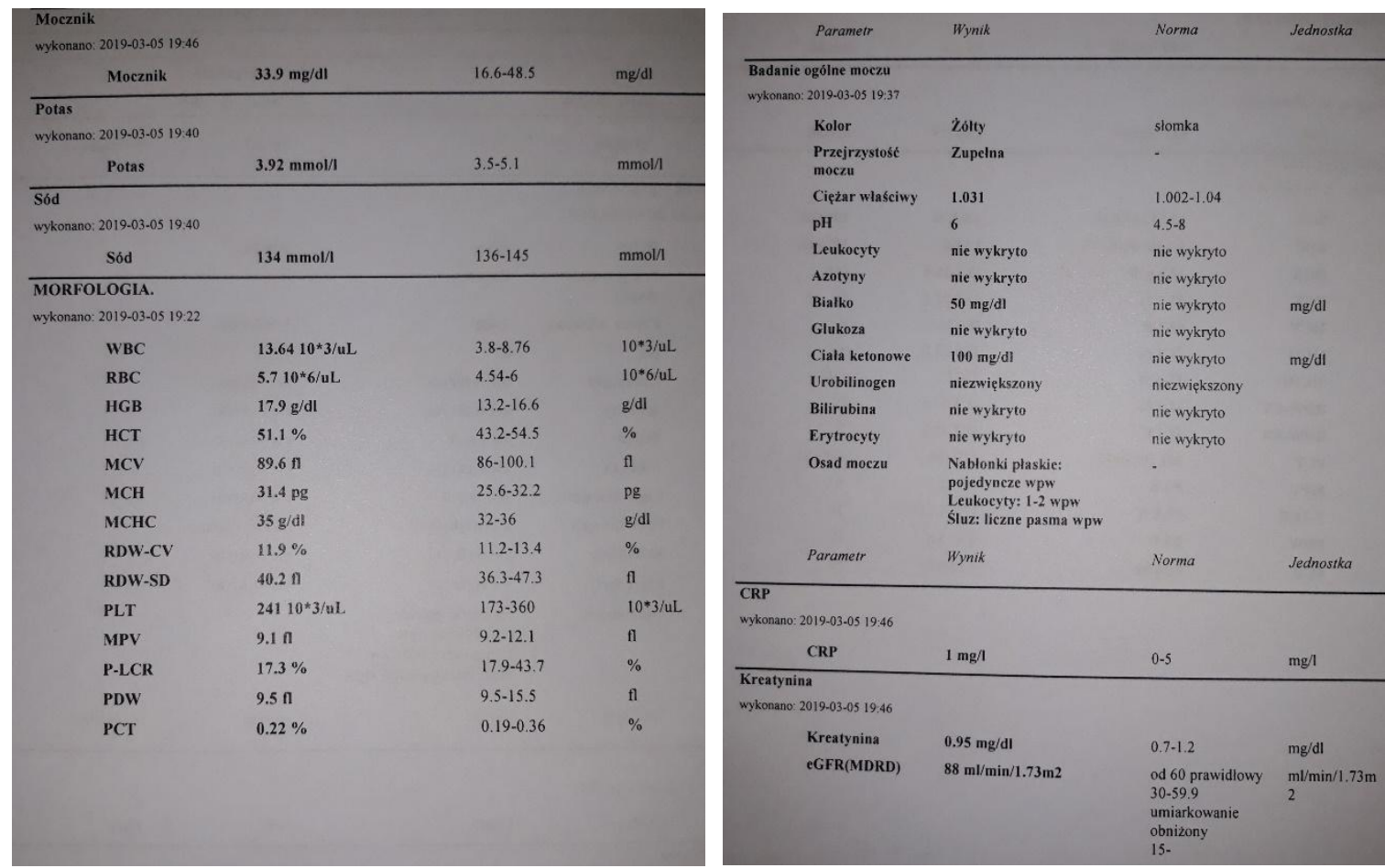

W badaniach laboratoryjnych stwierdzono:

Ponadto wykluczono infekcję C. difficile (nie stwierdzono obecności antygenu GDH ani toksyn A i B w próbce kału).

Z uwagi na brak poprawy po leczeniu zchowawczym w trakcie obserwacji w SOR, pacjent został przyjęty do Oddziału Chirurgicznego i zakwalifikowany do zabiegu operacyjnego. Wykonano laparotomię. Stwierdzono mętno-surowiczo-krwisty płyn w jamie brzusznej, jelito cienkie $\mathrm{z}$ cechami niedrożności. Wyrostek robaczkowy który uległ samoistnej amputacji był zmieniony zapalnie, oklejony szczelnie siecią. Usunięty wyrostek przesłano do badania histopatologicznego.

Zabieg i znieczulenie chory zniósł dobrze. Po zabiegu przewód pokarmowy uruchomiono $\mathrm{z}$ dobrą tolerancją stopniowo rozszerzając dietę. Chory został wypisany do domu w 3 dobie pooperacyjnej. W wyniku histopatologicznym wyrostka stwierdzono cechy przewlekłego zapalenia.

W przedstawionym powyżej przypadku klinicznym zmiany makroskopowe okolicy wyrostka robaczkowego i charakter płynu w jamie brzusznej pozwalają wnioskować o długotrwałym procesie zapalnym. Prawdopodobnie to ostre zapalenie wyrostka powodowało objawy kliniczne, z powodu których wykonano kolonoskopię. Badanie doprowadziło do samoamputacji wyrostka, która spowodowała nasilenie zgłaszanych dolegliwości. Obrazuje to jedynie jak bardzo podstępną chorobą jest appendcitis acuta oraz jak bogate spektrum objawów może prezentować.

$\mathrm{Z}$ drugiej strony przypadek ten porusza drażliwą kwestię istnienia "przewlekłego zapalenia wyrostka robaczkowego". Według powszechnej, „klasycznej” opinii charakterystyczną cechą ostrego zapalenia wyrostka są dolegliwości trwające 8 czy 12 godzin, choć w literaturze można też spotkać 48 godzin. 
Zagadnienie istnienia przewlekłego zapalenia wyrostka niejednokrotnie zostało już poruszone w literaturze. Cytując za W. Meyer-Marcotty oraz I. Plarre: „Z klinicznego punktu widzenia tzw. ,przewlekłe zapalenie wyrostka robaczkowego" nie istnieje” [3]. Mimo to w literaturze zachodniej można się natknąć na próby zdefiniowania tej jednostki chorobowej, która wg. Hawes A.S. oraz Whalen G.H. dotyczy około 1,5\% wszystkich przypadków zapalenia wyrostka [4].

Według S. Craig przewlekłe zapalenie wyrostka robaczkowego można rozpoznać gdy:

- ból nad prawym talerzem biodrowym trwa dłużej niż 3 tygodnie bez innej przyczyny;

- wycięcie wyrostka robaczkowego powoduje ustąpienie dolegliwości;

- badanie histopatologiczne ujawniło obecność przewlekłego czynnego zapalenia ściany wyrostka robaczkowego lub zwłóknienia wyrostka robaczkowego [5].

Inni poruszają możliwość występowania śródściennych zwapnień wyrostka widocznych na RTG przeglądowym jamy brzusznej, a będących wynikiem toczenia się przewlekłego zapalenia [6].

To czy wcześniejsze objawy można przypisać innej jednostce chorobowej, która była przyczyną zapalenia wyrostka czy samemu zapaleniu wyrostka jeszcze długo pozostanie nie rozstrzygnięte. Natomiast z pewnością można powtórzyć za Savrin R. A. i wsp. że wielu lekarzy nie akceptuje zapalenia wyrostka robaczkowego jako choroby przewlekłej lub nawracającej [7]. Mimo upływu lat to stwierdzenie dalej pozostaje aktualne.

Bibliografia:

[1] J. Cwaliński, T. Banasiewicz "Choroby wyrostka robaczkowego", "Chirurgia t.2" pod redakcją G. Wallnera, T. Banasiewicza, wyd. I

[2] J. Ciećkiewicz "Ostre zapaleni wyrostka rbaczkowego", "Interna Szczeklika - mały podręcznik" https://www.mp.pl/interna/chapter/B16.II.4.25.3.

[3] W. Meyer-Marcotty, I. Plarr, „Chronic appendicitis”; Langenbecks Arch Chir. 1986;369:187-90

[4] Hawes A.S., Whalen G.H. „Recurrent and chronic appendicitis: the other inflammatory conditions of the appendix". Am Surg. 1994; 60: 217

[5] Sandy Craig, „How is chronic appendicitis defined?” Jul 23, 2018 https://www.medscape.com/answers/773895-14452/how-is-chronic-appendicitis-defined

[6] Brøndum V., „Atypic appendicitis acuta”; Röntgen-Blätter, 1989 Mar;42(3):119-20.

[7] Savrin R.A., Clausen K., Martin E.W. Jr., Cooperman M.; „Chronic and recurrent appendicitis"; Am J Surg. 1979 Mar;137(3):355-7. 